\title{
Probiotic Lactobacillus rhamnosus GG mono-association suppresses human rotavirus-induced autophagy in the gnotobiotic piglet intestine
}

Shaoping Wu', Lijuan Yuan², Yongguo Zhang ${ }^{1}$, Fangning Liư', Guohua Li², Ke Wen², Jacob Kocher², Xingdong Yang ${ }^{2}$ and Jun Sun ${ }^{1 *}$

\begin{abstract}
Background: Human rotavirus (HRV) is the most important cause of severe diarrhea in infants and young children. Probiotic Lactobacillus rhamnosus GG (LGG) reduces rotavirus infection and diarrhea. However, the molecular mechanisms of LGG-mediated protection from rotavirus infection are poorly understood. Autophagy plays an essential role in responses to microbial pathogens. However, the role of autophagy in HRV infection and LGG treatment is unknown. We hypothesize that rotavirus gastroenteritis activates autophagy and that LGG suppresses virus-induced autophagy and prevents intestinal damage in infected piglets.
\end{abstract}

Methods: We used LGG feeding to combat viral gastroenteritis in the gnotobiotic pig model of virulent HRV infection.

Results: We found that LGG feeding did not increase autophagy, whereas virus infection induced autophagy in the piglet intestine. Virus infection increased the protein levels of the autophagy markers ATG16L1 and Beclin-1 and the autophagy regulator mTOR. LGG treatment during viral gastroenteritis reduced autophagy marker expression to normal levels, induced apoptosis and partially prevented virus-induced tissue damage.

Conclusion: Our study provides new insights into virus-induced autophagy and LGG suppression of uncontrolled autophagy and intestinal injury. A better understanding of the antiviral activity of LGG will lead to novel therapeutic strategies for infant infectious diseases.

Keywords: Autophagy, Apoptosis, Diarrhea, Gnotobiotic pig, Lactobacillus rhamnosus GG, Infectious disease, Intestinal inflammation, Intestinal injury, Probiotics, Rotavirus

\section{Introduction}

Autophagy is a lysosome-mediated catabolic pathway that occurs ubiquitously in all eukaryotic cells [1]. It is an immune mechanism that removes intracellular pathogens by the degradation of dysfunctional intracellular organelles. Mammalian autophagy involves initiation, nucleation, elongation, closure, maturation, and degradation [2]. Impaired autophagy has been linked to the pathogenesis of various diseases, including inflammatory bowel disease (IBD), ne

\footnotetext{
*Correspondence: jun_sun@rush.edu

'Department of Biochemistry, Rush University, Cohn Research Building, 1735

W. Harrison Street, Chicago, IL 60612, USA

Full list of author information is available at the end of the article
}

crotizing enterocolitis (NEC), tuberculosis neurodegeneration, and aging. Polymorphisms in two autophagyrelated genes-ATG16L1 and interferon-regulated GTPase (IRGM) - are strongly correlated with Crohn's disease (CD) $[3,4]$. Autophagy occurs in the intestinal epithelium of neonatal piglets [5], in the intestinal epithelium of NEC patients and in the ileum of NEC rats [6]. Multiple autophagy-related proteins control autophagosome formation. Activated mTOR, VPS34, and Beclin-1 (a mammalian homolog of yeast Atg6) are required to induce autophagy. Although it is unclear whether autophagy is a protective response or a deleterious process, it is clear that 
uncontrolled autophagy has adverse effects in certain pathological conditions, ultimately causing cell death.

Human rotavirus (HRV) is the most important cause of severe dehydrating diarrhea in infants and young children worldwide. Rotavirus hijacks autophagy and uses its membranes to transport viral proteins for the assembly of infectious particles at the sites of virus replication; inhibition of the autophagy signaling pathway blocks virus production [7]. Lactobacillus rhamnosus GG (LGG) is a probiotic strain that has reduced rotavirus diarrhea in many clinical trials [8-14]. The benefits of LGG therapy include reduced duration and incidence of rotavirus diarrhea, diminished rotavirus shedding, and increased production of rotavirusspecific antibodies. However, the molecular mechanisms of LGG protection from rotavirus diarrhea are not well understood.

In the current study, we hypothesized that autophagy is activated during viral gastroenteritis and that LGG suppresses the virus-induced autophagy to prevent intestinal damage in infected pigs. We measured the effects of continuous LGG feeding in the gnotobiotic $(\mathrm{Gn})$ pig model of virulent human rotavirus (HRV) gastroenteritis. Pigs were assigned to the following treatment groups: LGG plus HRV, HRV only, LGG only (LGG) or mock control. We investigated intestinal autophagy markers and pathologic changes in these groups. Here, we report that rotavirus infection alone, but not LGG alone, induced autophagy in the intestines of Gn pigs. LGG reduced the expression of autophagy markers to baseline levels and partially prevented tissue damage. Our study provides new insights into virus-induced autophagy and the role of LGG in suppressing autophagy and intestinal injury during viral gastroenteritis.

\section{Results}

Rotavirus infection, but not LGG treatment, induces autophagy in the $\mathrm{Gn}$ piglet intestine

We collected ileum tissues from the LGG mono-associated and/or rotavirus-infected Gn pigs on post-HRV inoculation day (PID) 2. We investigated the autophagy regulators mTOR and Class III PI3K VPS34 (also called PIK3C3) [15] and the autophagy markers ATG16L1 andBeclin-1. We found no significant changes in these markers in the pig intestine before or after LGG-monoassociation (Figure 1), indicating that LGG treatment alone had no effect on intestinal autophagy. In contrast, HRV infection elevated the protein levels of phospho-mTOR Ser 2448 (p-mTOR), mTOR, VPS34, Beclin-1, and ATG16L1 (Figure 1).

\section{LGG treatment protects the intestine from rotavirus- induced autophagy}

To determine the effects of probiotic LGG on auto phagy-related proteins, we immunoblotted for $\mathrm{p}-\mathrm{m}$ TOR, mTOR, VPS34, ATG16L1, and Beclin-1 in small

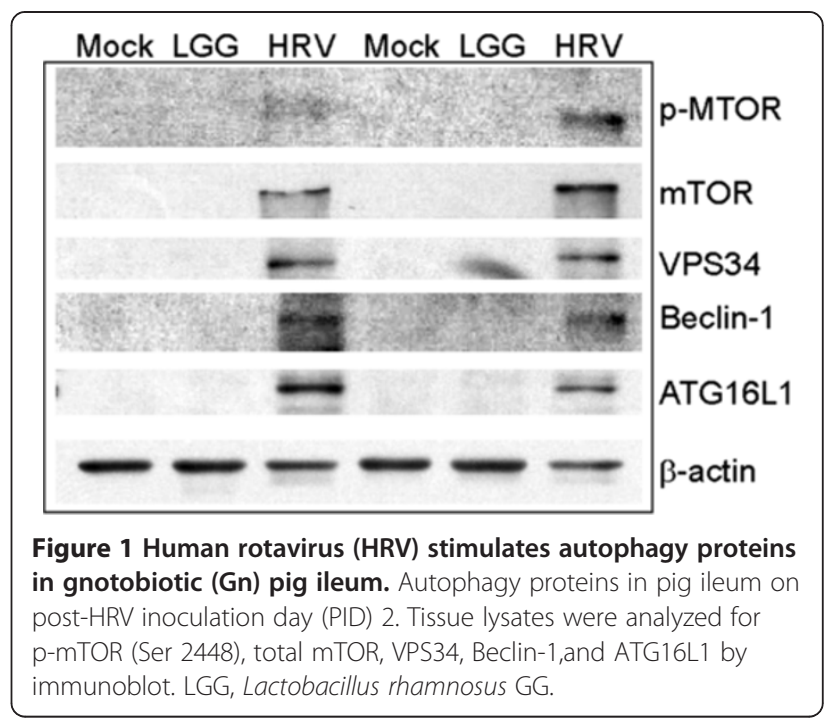

intestinal epithelial cells (Figure 2). LGG inhibited the expression of p-mTOR, mTOR, VPS34, Beclin-1 and ATG16L1, which were otherwise elevated by HRV infection (Figure 2).

\section{Location of autophagy markers in pig ileum}

We next investigated the location of autophagy markers in the pig ileum. In the mock control and LGG only groups, we noticed few p-mTOR-positive cells (Figure 3A). In the HRV-infected intestine, p-mTOR staining was more prevalent. LGG treatment decreased the number of $\mathrm{p}$ mTOR-positive cells in HRV-infected intestine. VPS34 levels were similar to those of p-mTOR; LGG treatment suppressed the number of VPS34-positive cells (Figure 3B). Furthermore, immunostaining showed that lysozyme was increased in ilea from HRV and LGG+HRV pigs compared with mock and LGG only pigs (Figure 3C), which was consistent with the real-time PCR result that rotavirus infection induced high levels of lysozyme mRNA (data not shown).

\section{LGG treatment induces apoptosis in HRV-infected intestinal cells}

Autophagy is a programmed survival strategy, whereas apoptosis is programmed cell death. We further examined the expression of apoptosis markers in the pig intestine (Figure 4A). p53 limits cellular proliferation by inducing cell cycle arrest and apoptosis in response to cellular stress [16,17]. LGG feeding with HRV infection led to higher p53 in the intestine of LGG+HRV pigs than in the other groups (Figure 4A). p53 staining showed an increased number of p53-positive cells in the ilea of the LGG+HRV group (Figure 4C). HRV infection also induced expression of the anti-apoptotic protein $\mathrm{Bcl}-2$ and the pro-survival marker $\mathrm{Bcl}-\mathrm{xl}$, and these 

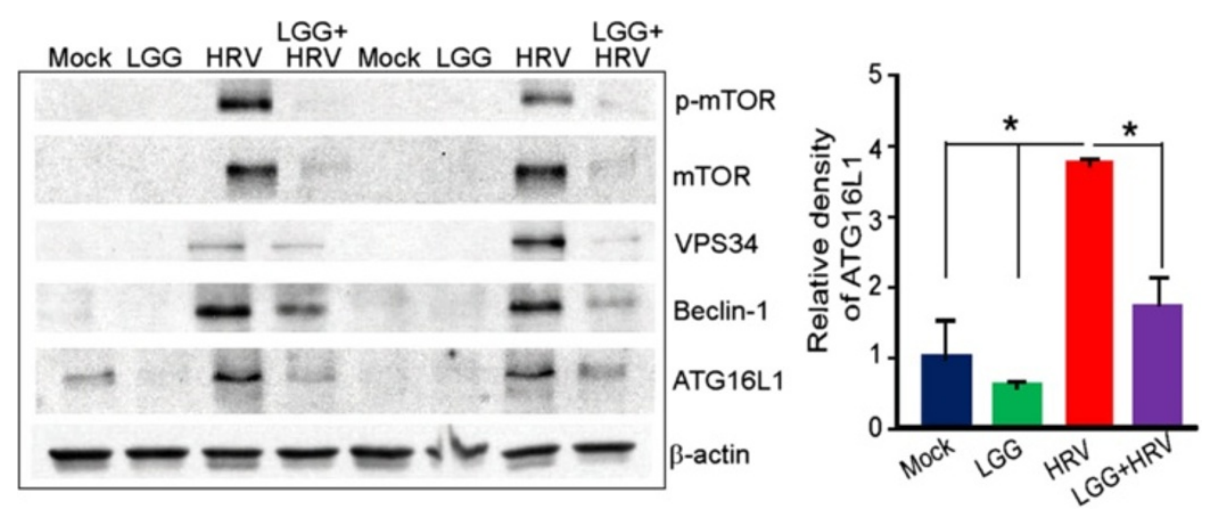

Figure 2 LGG inhibits autophagy proteins enhanced by HRV in Gn pig ileum. Autophagy proteins in pig ileum treated with LGG and HRV. lleum epithelia were scraped on PID 2. Relative protein band intensities of ATG16L1 in pig ileum were analyzed with NIH image. Data are reported as the mean $\pm S D$. ANOVA, ${ }^{*} P<0.05$.

proteins were significantly decreased by LGG feeding (Figure 4A).

Bax is a pro-apoptotic Bcl-2-family protein [18] that resides in the cytosol and translocates to mitochondria upon induction of apoptosis [19]. While HRV infection suppressed Bax expression, LGG feeding inhibited this suppression of Bax, although there were no differences between the HRV and LGG+HRV pigs (Figure 4A). Bax also regulates caspase activity $[20,21]$. We measured cleaved caspase-3 to quantify cell apoptosis. The LGG+ HRV pigs developed a higher ratio of cleaved caspase-3 to pro-caspase-3 (Figure 4B).
We then investigated the location of p53 in pig ileum. There were more p53-positive cells in the LGG+HRV pigs than in LGG and HRV only pigs (Figure 4C). Thus, LGG feeding increased the number of p53-positive intestinal cells in HRV-infected pigs. The localization of cleaved caspase-3 was similar to p53; LGG treatment enhanced the number of cleaved caspase-3-positive cells (Figure 4C).

\section{LGG feeding protects intestine physiology after} virus infection

LGG may suppress uncontrolled autophagy, thus protecting the intestine from injury during viral gastroenteritis.

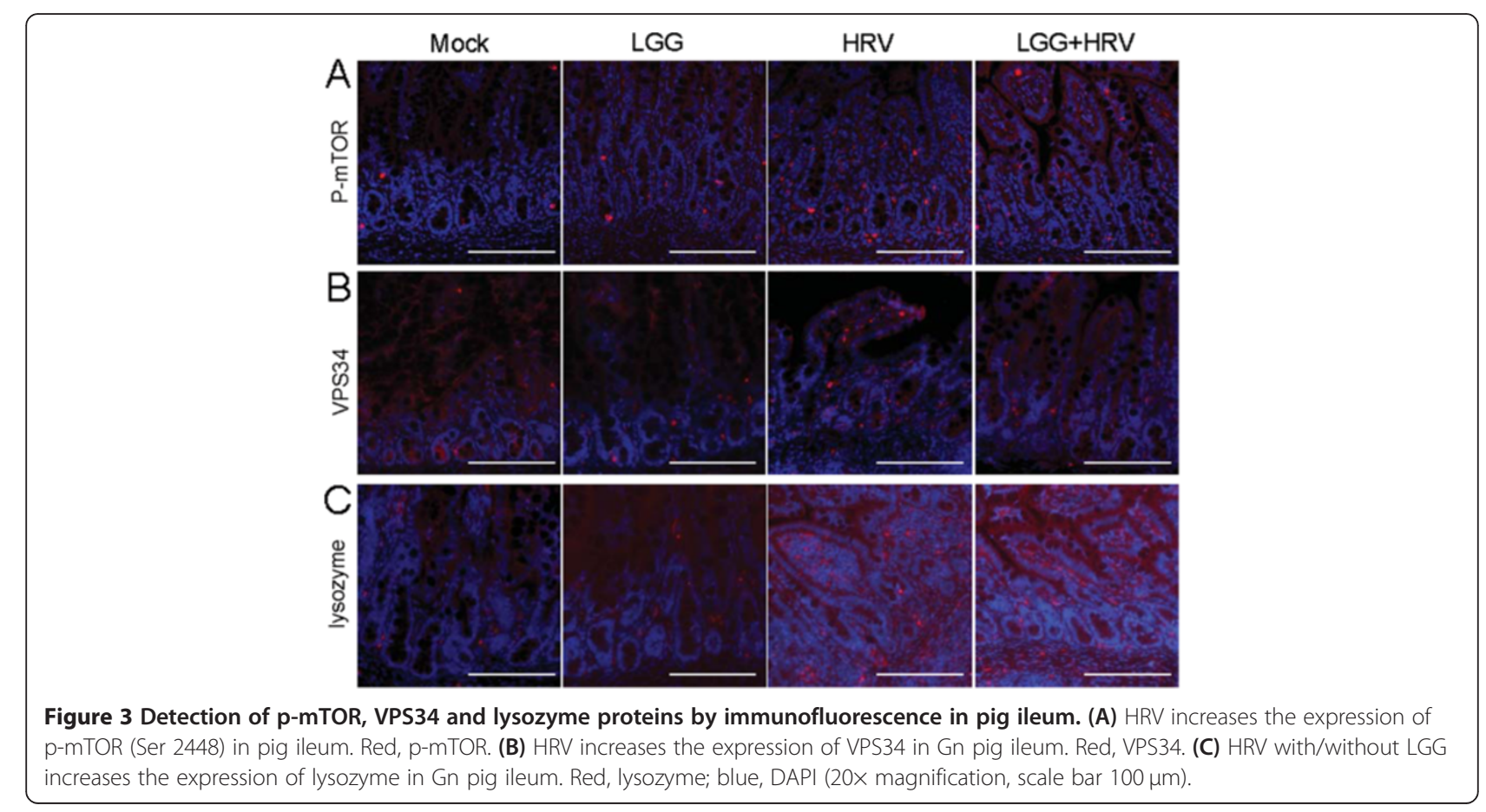




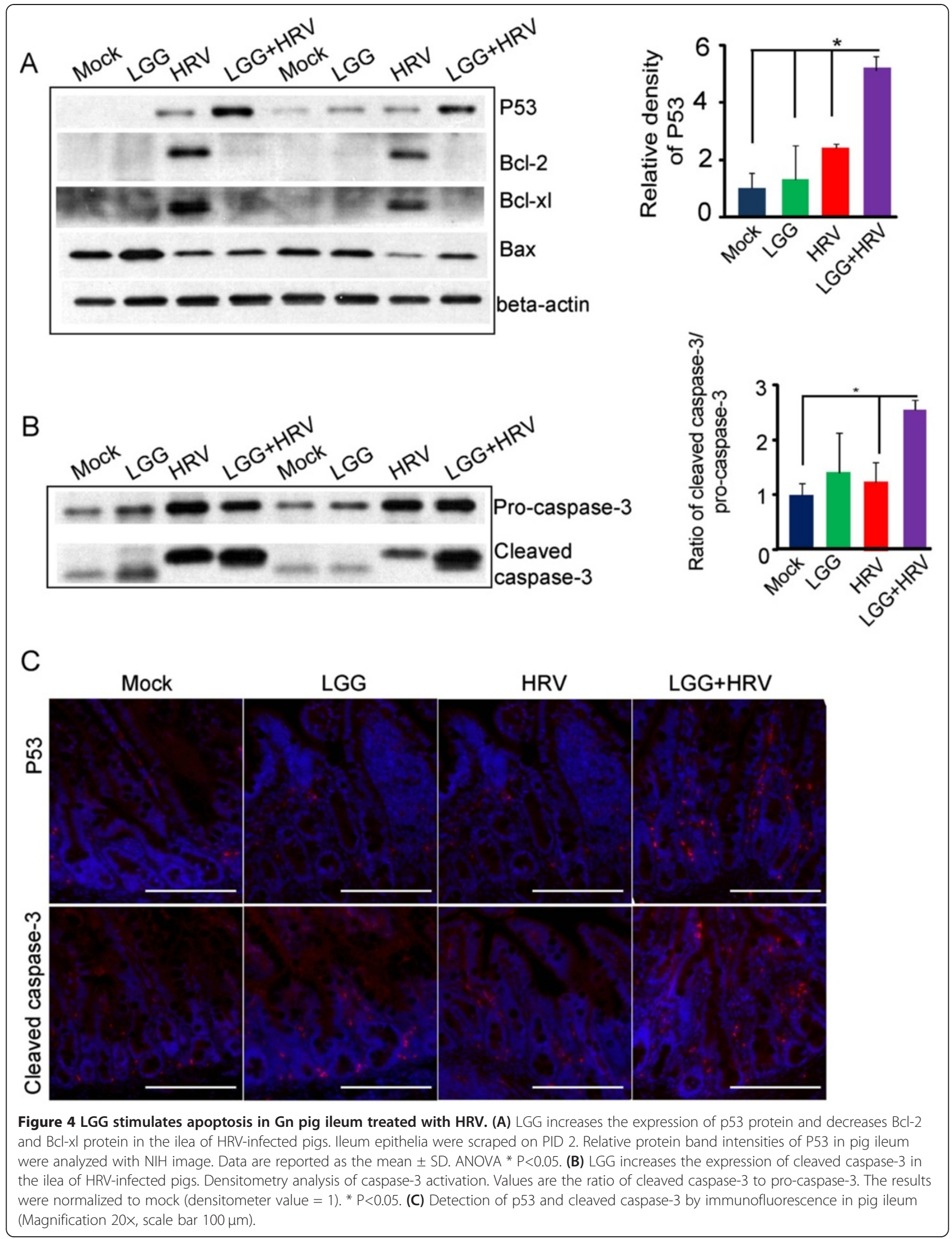


By H\&E staining, we observed vigorous immune infiltration (yellow arrow) and discontinued muscularis mucosae (green arrow) in pig ileum infected with HRV (Figure 5A), but the LGG-treated infected ileum had less inflammation. LGG helped to maintain intestinal epithelial integrity. Claudin-2 is a 'leaky' claudin that forms a water channel, which mediates paracellular water transport in leaky epithelia [22-26]. Western blotting showed that virus infection increased the expression of claudin-2, whereas LGG treatment lowered the claudin-2 level after infection (Figure 5B). This result may explain our observations that LGG-treated piglets were less likely to develop HRV diarrhea and had a shorter mean duration of diarrhea compared with the non-treated group (data not shown). Our previous study and unpublished data showed that nontreated infected pigs had worse clinical and histopathological outcomes than the LGG+HRV group. Virus shedding was also lower in the LGG-treated pigs compared with the non-treated HRV group (data not shown).

\section{Discussion}

In summary, our current studies made specific advances and uncovered several novel aspects of autophagy in rotavirus infection and probiotic protection: (1) rotavirus infection enhanced autophagy in the pig small intestine; (2) compared with mock treatment, oral LGG treatment in the Gn pig model did not change the expression of autophagy markers; and (3) LGG may suppress viral gastroenteritis by controlling the virus-induced autophagy responses in the intestine. Impaired autophagy is associated with the pathogenesis of various infectious diseases. Our data show that while rotavirus activated autophagy in the intestine at PID 2, LGG treatment down-regulated autophagy in response to viral infection, providing a balance between apoptosis and autophagy in the infected intestine (Figure 5C). In HRV-infected cells, LGG promotes apoptosis, which restricts virus spread to neighboring epithelia. LGG reduces rotavirus replication by suppressing the expression of autophagy proteins, which in turn impairs the assembly of infectious rotavirus particles [7]. Our study suggests a new molecular mechanism by which LGG suppresses uncontrolled autophagy and intestinal injury during viral gastroenteritis. Autophagy and apoptosis are connected both positively and negatively, and extensive crosstalk exists between them. Because our data showed that LGG-treated intestine had more apoptotic cells, LGG-induced apoptosis could help the host clear infected cells.

LGG treatment in infected Gn pigs reduced the expression of p-mTOR, total mTOR, VPS34, and Beclin-1 to normal levels in intestinal epithelial cells. These data suggest that LGG suppressed autophagy at the stage of initiation. Recent studies indicate that rotavirus and coronavirus hijack autophagy in the host $[7,27]$. Our data suggest that well-controlled autophagy is necessary to protect the host intestine from injury.

The Gn pig model allowed us to observe the effects of continuous LGG feeding on HRV gastroenteritis in a relatively clean background and well-controlled system. This model ensured that the data were not confounded by other microbes present in conventionally reared pigs. The gastrointestinal physiology and immune system in piglets closely mimic those of human infants [28]. However, we also recognize the limitations of the current studies. We had limited number of piglets in the experimental groups. We could not use a genetically engineered pig model to further investigate the host autophagy responses or the genes that mediate the protective role of LGG. In an in vitro experiment, we investigated autophagy after virus infection and LGG treatment in a pig intestinal epithelial cell line [29], but we did not observe responses similar to those in vivo. Moreover, some antibodies against the relevant porcine proteins are not commercially available. Regardless of the limitation, our current findings have their novelty in studying virusinduced autophagy and LGG suppression of uncontrolled autophagy in vivo.

In conclusion, we observed that LGG suppressed autophagy during rotaviral diarrhea. LGG treatment reduced rotavirus shedding and the incidence and duration of rotavirus diarrhea. We speculate that these probiotic effects are due to the regulation of autophagy in the intestine. Notably, we provide the first evidence of virus-induced autophagy in a well-controlled experimental gnotobiotic piglet model. LGG therapy has clear beneficial effects that protect the host from rotavirus diarrhea. Thus, a better understanding of the protective role of LGG during viral pathogenesis will lead to novel therapies for infectious diseases.

\section{Methods}

\section{Ethics statement}

The animal experiments in this study were approved (\#10168-CVM) by the Institutional Animal Care and Use Committee of The Virginia Polytechnic Institute and State University. The Virginia-Maryland Regional College of Veterinary Medicine (VMRCVM) is fully accredited by the American Association for Accreditation of Laboratory Animal Care (AAALAC) and approved by the Office of Laboratory Animal Welfare (OLAW) in compliance with the Public Health Service Policy on Humane Care and Use of Laboratory Animals. Euthanasia of pigs was conducted using a method consistent with the recommendations of the Panel on Euthanasia of the American Veterinary Medical Association. 


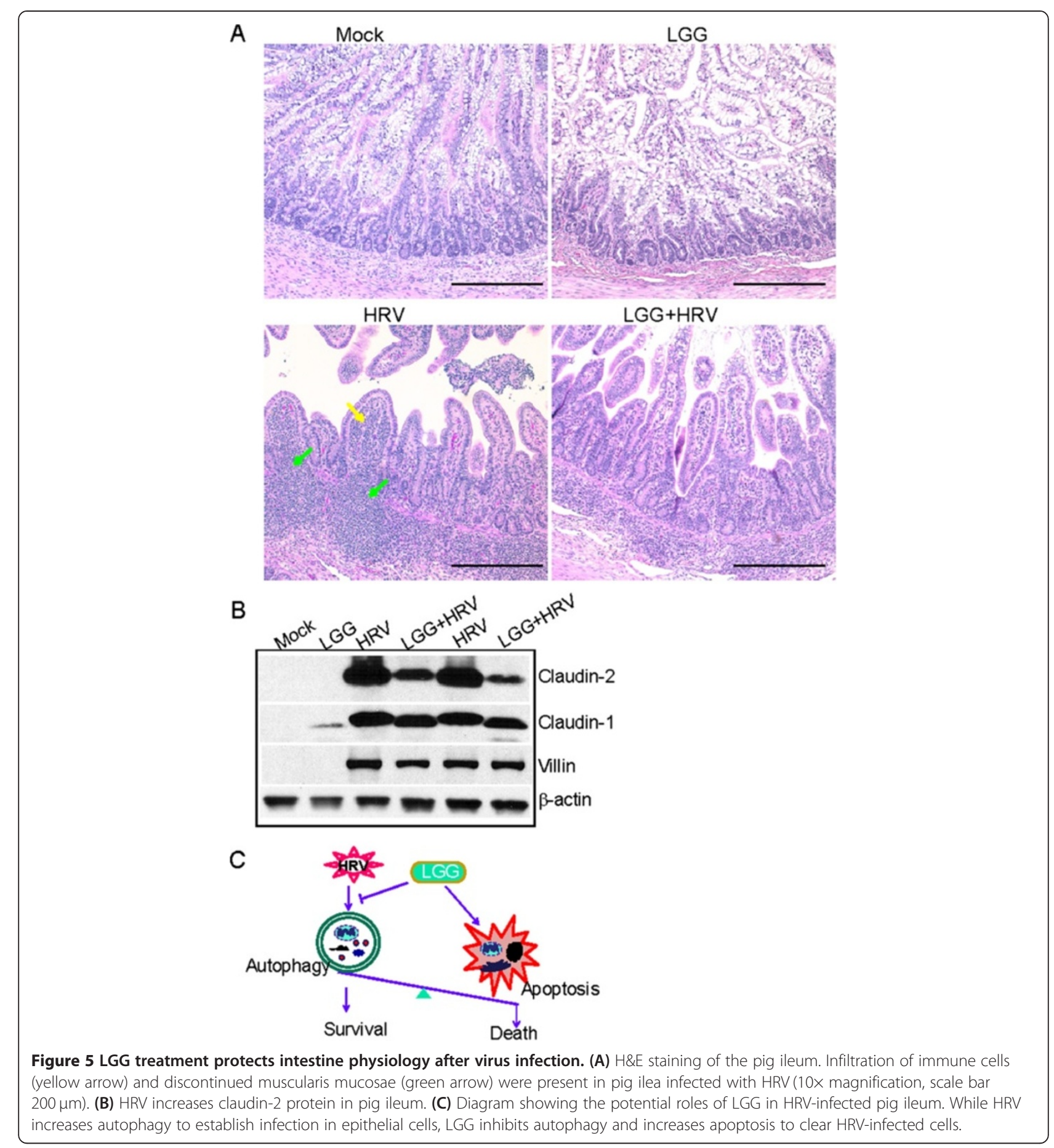

\section{Rotavirus}

The HRV Wa strain (G1P1A [14]) (from Dr. Linda Saif, The Ohio State University, USA) was passaged in Gn pigs, and the pooled intestinal contents of pigs were used for inoculation at a dose of $\sim 10^{5}$ fluorescence forming units (FFU). The $50 \%$ infectious dose ( $\mathrm{ID}_{50}$ ) of HRV in neonatal Gn pigs was determined to be approximately 1 FFU [30]. The virus titer was determined by cell culture immunofluorescence (CCIF) and was expressed as FFU/ $\mathrm{ml}$, as described previously [29].

\section{Probiotic bacteria strain}

Lactobacillus rhamnosus GG (ATCC, 53103) cultures were anaerobically propagated (85\% nitrogen, $10 \%$ hydrogen, $5 \%$ carbon dioxide) in Lactobacilli MRS broth (Weber Scientific, 3113-60) overnight at $37^{\circ} \mathrm{C}$ in sealed Gaspak 
jars containing Anaerogen packs. Bacterial suspensions (MRS with $15-20 \%$ glycerol) were stored at $-80^{\circ} \mathrm{C}$. Bacteria were titrated on MRS agar plates and quantified as CFU per ml, as described previously [31,32]. Prior to feeding, the bacteria were thawed, washed 2 times with $0.1 \%$ peptone water, centrifuged at $2000 \mathrm{rpm}$ for $10 \mathrm{~min}$ at $4^{\circ} \mathrm{C}$ and diluted to specified $\mathrm{CFU} / \mathrm{ml}$.

\section{Gnotobiotic pig treatment}

Near-term pigs were surgically removed from pregnant sows (Large White cross bred) and maintained in Gn isolator units as described [33]. All pigs were confirmed as germ-free prior to LGG feeding and sera negative for rotavirus antibodies prior to HRV exposure. Pigs (both males and females) were randomly assigned to four treatment groups as follows: (1) LGG colonization plus HRV infection (LGG+HRV), (2) HRV only (HRV), (3) LGG only (LGG) or (4) mock control (Mock). At 3 days of age (post-LGG feeding day, pigs in LGG groups were orally dosed with $10^{3}$ CFU LGG in $3 \mathrm{ml}$ of $0.1 \%$ peptone water, and the daily LGG dose increased by 10 -fold each day up to $10^{12}$ CFU. The incremental increases in LGG doses were determined empirically to avoid causing diarrhea by high doses of probiotic bacteria during the first few days of life, as $\mathrm{Gn}$ pigs lack maternal antibodies. The pigs were then fed $10^{12}$ CFU every day until euthanasia. Pigs in non-LGG groups were given an equal volume of $0.1 \%$ peptone water. At PFD 9 (post-HRV inoculation day [PID] 0), pigs in HRV groups were orally inoculated with $10^{5}$ FFU HRV in $5 \mathrm{ml}$ Diluent \#5 (Modified Eagle Medium with $1 \%$ non-essential amino acids, $1 \%$ antibiotics [penicillin 10,000 I.U./ml + streptomycin 10,000 $\mathrm{MCG} / \mathrm{ml}+\operatorname{amphotericin} 25 \mathrm{MCG} / \mathrm{ml}]$ ), and pigs in non-HRV groups were orally inoculated with an equal volume of Diluent \#5. Pigs were given $8 \mathrm{ml}$ of $100 \mathrm{mM}$ sodium bicarbonate $20 \mathrm{~min}$ before HRV inoculation to reduce gastric acidity. Pigs were euthanized for sample collection on PFD11 (PID 2).

\section{Histology and immunofluorescence staining}

Distal ileal tissues were freshly isolated and paraffinembedded after fixation with $10 \%$ neutral buffered formalin. For histology, the slides were processed with Hematoxylin-Eosin (H\&E) staining and observed under a microscope. Immunofluorescence was performed on paraffin-embedded sections $(5 \mu \mathrm{m})$. After preparation of the slides as described previously [34], tissue samples were incubated with anti-lysozyme (Santa Cruz, sc27958), antip-mTOR (Ser 2448) (Cell Signaling, 5536), anti-VPS34 (Invitrogen, 382100), anti-p53 (Santa Cruz, sc-126), or anti-cleaved caspase-3 (Biocare Medical, CP229C). Samples were then incubated with Donkey anti-goat Alexa Fluor 594 (Invitrogen, A11058), goat anti-rabbit Alexa Fluor 594 (Invitrogen, A11037) or goat anti- mouse Alexa Fluor 594 (Invitrogen, A11032) and DAPI (Invitrogen, D1306) for 1 hour at room temperature. Tissues were mounted with SlowFade (Invitrogen, S2828) under a cover slip, and the edges were sealed to prevent drying. Specimens were examined with a Leica SP5 Laser confocal microscope.

\section{Western blot analysis and antibodies}

Autophagy and apoptosis-related proteins were detected by western blot of pig ileum sections and ileal epithelial cells. The ileal epithelial cells were collected by cutting or scraping, as previously described [35]. Briefly, epithelial cells were lysed in a lysis buffer (1\% Triton X-100, $150 \mathrm{mmol} / \mathrm{L} \mathrm{NaCl}, 10 \mathrm{mmol} / \mathrm{L}$ Tris $\mathrm{pH} \mathrm{7.4,} 1 \mathrm{mmol} / \mathrm{L}$ EDTA, $1 \mathrm{mmol} / \mathrm{L}$ EGTA pH 8.0, $0.2 \mathrm{mmol} / \mathrm{L}$ sodium ortho-vanadate) containing a protease inhibitor cocktail (Roche Diagnostics, 11836170001). Equal amounts of protein were separated by SDS-polyacrylamide gel electrophoresis, transferred to nitrocellulose (Bio-Rad, 1620112), and immunoblotted with the following primary antibodies: anti-phospho-mTOR (ser2448) (Cell Signaling, 5536), anti-mTOR (Cell Signaling, 2983), anticaspase-3 (Cell Signaling, 9665), anti-VPS34 (Invitrogen, 382100), anti-Beclin-1 (Santa Cruz, sc-10086), anti-P53 (Santa Cruz, sc-126), anti-Bcl-2 (Santa Cruz, sc-7382), anti-Bcl-xl (Santa Cruz ,sc-8392), anti-Villin (Santa Cruz, sc-7672), anti-ATG16l1 (Abgent, AP18176), or anti- $\beta$ actin (Sigma-Aldrich, A5441). Proteins were visualized by ECL chemiluminescence. Protein bands of interest were quantitated densitometrically and normalized to $\beta$-actin.

\section{Competing interests}

The authors declare that they have no competing interests.

\section{Authors' contributions}

$\mathrm{SW}, \mathrm{YZ}, \mathrm{FL}, \mathrm{GL}, \mathrm{KW}, \mathrm{JK}, \mathrm{XY}$ : performing experiments, contribution to concept and design, analysis and interpretation of data, and important intellectual input in drafting or revising the manuscript. LY, JS: contribution to concept and design, analysis and interpretation of data, and important intellectual input in drafting or revising the manuscript.

\section{Acknowledgements}

We thank Dr. Marlice Vonck, Dr. Kevin Pelzer, Pete Jobst, Andrea Aman, Shannon Viers, and Tammy Buifor animal care. This work was supported by the NCCAM, the National Institutes of Health (R01AT004789 to L. Yuan), NIDDK (KO1 DK075386 and 1R03DK089010-01), the American Cancer Society (RSG-09-075-01-MBC), and a Swim Across America Cancer Research Award to J. Sun.

\section{Author details}

'Department of Biochemistry, Rush University, Cohn Research Building, 1735 W. Harrison Street, Chicago, IL 60612, USA. ${ }^{2}$ Department of Biomedical Sciences and Pathobiology, Virginia-Maryland Regional College of Veterinary Medicine, Virginia Polytechnic Institute and State University, Integrated Life Science Building, 1981 Kraft Dr, Blacksburg, VA 24061-0913, USA.

Received: 16 June 2013 Accepted: 25 July 2013

Published: 7 August 2013

\section{References}

1. Reggiori F, Klionsky DJ: Autophagy in the eukaryotic cell. Eukaryot Cell 2002, 1:11-21. 
2. Kang R, Zeh HJ, Lotze MT, Tang D: The Beclin 1 network regulates autophagy and apoptosis. Cell Death Differ 2011, 18:571-580.

3. Rioux JD, Xavier RJ, Taylor KD, Silverberg MS, Goyette P, Huett A, Green T, Kuballa P, Barmada MM, Datta LW, et al: Genome-wide association study identifies new susceptibility loci for Crohn disease and implicates autophagy in disease pathogenesis. Nat Genet 2007, 39:596-604.

4. Parkes M, Barrett JC, Prescott NJ, Tremelling M, Anderson CA, Fisher SA, Roberts RG, Nimmo ER, Cummings FR, Soars D, et al: Sequence variants in the autophagy gene IRGM and multiple other replicating loci contribute to Crohn's disease susceptibility. Nat Genet 2007, 39:830-832.

5. Godlewski MM, Hallay N, Bierla JB, Zabielski R: Molecular mechanism of programmed cell death in the gut epithelium of neonatal piglets. J Physiol Pharmacol 2007, 58(Suppl 3):97-113.

6. Maynard AA, Dvorak K, Khailova L, Dobrenen H, Arganbright KM, Halpern MD, Kurundkar AR, Maheshwari A, Dvorak B: Epidermal growth factor reduces autophagy in intestinal epithelium and in the rat model of necrotizing enterocolitis. Am J Physiol Gastrointest Liver Physiol 2010 299:G614-G622.

7. Crawford SE, Hyser JM, Utama B, Estes MK: Autophagy hijacked through viroporin-activated calcium/calmodulin-dependent kinase kinase-beta signaling is required for rotavirus replication. Proc Natl Acad Sci USA 2012, 109:E3405-E3413.

8. Szajewska H, Skorka A, Ruszczynski M, Gieruszczak-Bialek D: Meta-analysis: Lactobacillus GG for treating acute diarrhoea in children. Aliment Pharmacol Ther 2007, 25:871-881.

9. Guandalini S: Probiotics for children with diarrhea: an update. J Clin Gastroenterol 2008, 42(Suppl 2):S53-S57.

10. Teran CG, Teran-Escalera CN, Villarroel P: Nitazoxanide vs. probiotics for the treatment of acute rotavirus diarrhea in children: a randomized, single-blind, controlled trial in Bolivian children. Int J Infect Dis 2009, 13:518-523.

11. Guandalini S: Probiotics for children: use in diarrhea. J Clin Gastroenterol 2006, 40:244-248.

12. Rosenfeldt $\mathrm{V}$, Michaelsen $\mathrm{KF}$, Jakobsen $\mathrm{M}$, Larsen $\mathrm{CN}$, Moller $\mathrm{PL}$, Pedersen $\mathrm{P}$, Tvede M, Weyrehter $\mathrm{H}$, Valerius NH, Paerregaard A: Effect of probiotic Lactobacillus strains in young children hospitalized with acute diarrhea. Pediatr Infect Dis J 2002, 21:411-416.

13. Guandalini S, Pensabene L, Zikri MA, Dias JA, Casali LG, Hoekstra H, Kolacek S, Massar K, Micetic-Turk D, Papadopoulou A, et al: Lactobacillus GG administered in oral rehydration solution to children with acute diarrhea: a multicenter European trial. J Pediatr Gastroenterol Nutr 2000 30:54-60.

14. Szajewska $H$, Wanke M, Patro B: Meta-analysis: the effects of Lactobacillus rhamnosus GG supplementation for the prevention of healthcareassociated diarrhoea in children. Aliment Pharmacol Ther 2011, 34:1079-1087

15. Jaber N, Dou Z, Chen JS, Catanzaro J, Jiang YP, Ballou LM, Selinger E, Ouyang X, Lin RZ, Zhang J, Zong WX: Class III PI3K Vps34 plays an essential role in autophagy and in heart and liver function. Proc Natl Acad Sci USA 2012, 109:2003-2008.

16. Donauer J, Schreck I, Liebel U, Weiss C: Role and interaction of p53, BAX and the stress-activated protein kinases p38 and JNK in benzo(a) pyrene-diolepoxide induced apoptosis in human colon carcinoma cells. Arch Toxicol 2012, 86:329-337.

17. Dai C, Tang Y, Jung SY, Qin J, Aaronson SA, Gu W: Differential effects on p53-mediated cell cycle arrest vs. apoptosis by p90. Proc Natl Acad Sci USA 2011, 108:18937-18942.

18. Oltvai ZN, Milliman $\mathrm{CL}$, Korsmeyer $\mathrm{SJ}$ : $\mathrm{BCl}-2$ heterodimerizes in vivo with a conserved homolog, Bax, that accelerates programmed cell death. Cell 1993, 74:609-619.

19. Hsu YT, Wolter KG, Youle RJ: Cytosol-to-membrane redistribution of Bax and Bcl-X(L) during apoptosis. Proc Natl Acad Sci USA 1997, 94:3668-3672

20. Finucane DM, Bossy-Wetzel E, Waterhouse NJ, Cotter TG, Green DR: Bax-induced caspase activation and apoptosis via cytochrome $\mathrm{c}$ release from mitochondria is inhibitable by Bcl-xL. J Biol Chem 1999, 274:2225-2233.

21. Cregan SP, MacLaurin JG, Craig CG, Robertson GS, Nicholson DW, Park DS, Slack RS: Bax-dependent caspase-3 activation is a key determinant in p53-induced apoptosis in neurons. J Neurosci 1999, 19:7860-7869.

22. Zeissig S, Burgel N, Gunzel D, Richter J, Mankertz J, Wahnschaffe U, Kroesen AJ, Zeitz M, Fromm M, Schulzke JD: Changes in expression and distribution of claudin 2, 5 and 8 lead to discontinuous tight junctions and barrier dysfunction in active Crohn's disease. Gut 2007, 56:61-72.

23. Rosenthal R, Milatz S, Krug SM, Oelrich B, Schulzke JD, Amasheh S, Gunzel D, Fromm M: Claudin-2, a component of the tight junction, forms a paracellular water channel. J Cell Sci 2010, 123:1913-1921.

24. Schulzke JD, Fromm M: Tight junctions: molecular structure meets function. Ann N Y Acad Sci 2009, 1165:1-6.

25. Van-Itallie CM, Holmes J, Bridges A, Anderson JM: Claudin-2-dependent changes in noncharged solute flux are mediated by the extracellular domains and require attachment to the PDZ-scaffold. Ann N Y Acad Sci 2009, 1165:82-87.

26. Holmes JL, Van-Itallie CM, Rasmussen JE, Anderson JM: Claudin profiling in the mouse during postnatal intestinal development and along the gastrointestinal tract reveals complex expression patterns. Gene Expr Patterns 2006, 6:581-588.

27. Reggiori F, Monastyrska I, Verheije MH, Cali T, Ulasli M, Bianchi S, Bernasconi R, de-Haan CA, Molinari M: Coronaviruses Hijack the LC3-I-positive EDEMosomes, ER-derived vesicles exporting short-lived ERAD regulators, for replication. Cell Host Microbe 2010, 7:500-508.

28. Patterson JK, Lei XG, Miller DD: The pig as an experimental model for elucidating the mechanisms governing dietary influence on mineral absorption. Exp Biol Med (Maywood) 2008, 233:651-664.

29. Liu F, Li G, Wen K, Bui T, Cao D, Zhang Y, Yuan L: Porcine small intestinal epithelial cell line (IPEC-J2) of rotavirus infection as a new model for the study of innate immune responses to rotaviruses and probiotics. Viral Immunol 2010, 23:135-149.

30. Ward LA, Rosen BI, Yuan L, Saif LJ: Pathogenesis of an attenuated and a virulent strain of group A human rotavirus in neonatal gnotobiotic pigs. J Gen Virol 1996, 77(Pt 7):1431-1441.

31. Zhang W, Azevedo MS, Gonzalez AM, Saif LJ, Van-Nguyen T, Wen K, Yousef $A E$, Yuan L: Influence of probiotic Lactobacilli colonization on neonatal $B$ cell responses in a gnotobiotic pig model of human rotavirus infection and disease. Vet Immunol Immunopathol 2008, 122:175-181.

32. Zhang W, Wen K, Azevedo MS, Gonzalez A, Saif LJ, Li G, Yousef AE, Yuan L: Lactic acid bacterial colonization and human rotavirus infection influence distribution and frequencies of monocytes/macrophages and dendritic cells in neonatal gnotobiotic pigs. Vet Immunol Immunopathol 2008, 121:222-231.

33. Wen K, Azevedo MS, Gonzalez A, Zhang W, Saif LJ, Li G, Yousef A, Yuan L: Toll-like receptor and innate cytokine responses induced by lactobacilli colonization and human rotavirus infection in gnotobiotic pigs. Vet Immunol Immunopathol 2009, 127:304-315.

34. Lu R, Wu S, Liu X, Xia Y, Zhang YG, Sun J: Chronic effects of a Salmonella type III secretion effector protein AvrA in vivo. PLoS One 2010, 5:e10505.

35. Wu S, Liao AP, Xia Y, Li YC, Li JD, Sartor RB, Sun J: Vitamin D receptor negatively regulates bacterial-stimulated NF-kappaB activity in intestine. Am J Pathol 2010, 177:686-697.

doi:10.1186/1757-4749-5-22

Cite this article as: Wu et al:: Probiotic Lactobacillus rhamnosus GG mono-association suppresses human rotavirus-induced autophagy in the gnotobiotic piglet intestine. Gut Pathogens 2013 5:22.

\section{Submit your next manuscript to BioMed Central and take full advantage of:}

- Convenient online submission

- Thorough peer review

- No space constraints or color figure charges

- Immediate publication on acceptance

- Inclusion in PubMed, CAS, Scopus and Google Scholar

- Research which is freely available for redistribution 